\title{
Activation of Themes During Narrative Reading
}

\author{
Hao Zhang \\ Department of Educational Psychology and Center for Cognitive Sciences \\ The University of Minnesota, Minneapolis
}

\author{
Rumjahn Hoosain \\ Department of Psychology \\ The University of Hong Kong
}

\begin{abstract}
The theme of a narrative text is its main point or moral that is often implied between lines. A rapid serial visual presentation procedure (RSVP) was used to examine the online status of generation of thematic inference during narrative text comprehension. In Experiment 1, the target words were presented in different contexts with different time courses. The results showed that the facilitative effects of inferential contexts were significant for target words at the RSVP rate of $400 \mathrm{~ms}$ and stimulus onset asynchrony of $600 \mathrm{~ms}$. There were no facilitative effects below this threshold. In Experiment 2, the location of target words was manipulated while maintaining the same presentation times. Further observed were facilitative effects of inferential contexts on target words appearing at the end of all the texts and at the middle of the texts when the reader had the correct expectation of the outcome in a text. These results suggested that thematic inference is normally generated online during comprehension. These findings indicate that the global theme of a narrative text is a fundamental component of text representation in reading. The result provides support for the constructionist theory of inference generation and the importance of theme information in constructing a coherent text representation.
\end{abstract}

When people read a narrative text, they understand the characters and episodes in the text. More important, they also understand the theme of the text that captures the overall meaning. The theme of a narrative text is its main point or moral that

Correspondence and requests for reprints should be sent to Hao Zhang, The University of Minnesota, Department of Educational Psychology and Center for Cognitive Sciences, Minneapolis, MN 55455. E-mail: zhang194@umn.edu 
readers can relate to their own lives. The roles of the theme have been investigated in terms of both text comprehension and memory (e.g., Bower, Black, \& Turner, 1979; Bransford \& Johnson, 1972; Graesser, Golding, \& Long, 1991; Graesser, Gordon, \& Sawyer, 1979; Graesser \& Nakamura, 1982; Williams, 1993). However, there is little consensus about what exactly a theme is. Generally speaking, the meaning of theme has been addressed in three facets: (a) The theme of a narrative amounts to a generalized declarative statement such as an adage, (b) the theme of a narrative text is expressed as a content word about the topic of the text, and (c) the theme of a narrative text is about a thematic abstract unit (TAU) that represents the thematic structure of an episode but serves many episodes in memory representation (e.g., Graesser, Pomeroy, \& Craig, 2002; Kurtz \& Schober, 2001). For Aesop's fable, "The Tortoise and the Hare," the first facet of the theme would be, "slow and steady wins the race," whereas the second facet could be "a race." The first two facets are involved in psychological research. The third facet of theme is based on computational perspective that emphasizes that themes are constructed from configurations of primitive plot units with dynamic goals and plans. However, there are few psychological studies related to the thematic computational approach. This study focuses on psychological approach to answer the question of activation of theme in narrative text reading.

Empirical evidence indicates that when readers comprehend a narrative text, they attempt to build a mental representation by making inferences to cohere with the explicit contents in the text. A central concern regarding the generation of inferences over the past decade is which inferences are normally generated online (Balota, Flores d'Arcais, \& Rayner, 1990; Graesser \& Bower, 1990; Greasser \& Kreuz, 1993; Greasser, Singer, \& Trabasso, 1994; Kintsch, 1993; Magliano \& Greasser, 1991; McKoon \& Ratcliff, 1992; Seifert, Robertson, \& Black, 1985; Singer, 1988; Whitney, 1987). Online inference means that an inference is generated during comprehension, whereas offline inference is constructed in a later retrieval task. The identification of online status distinguishes whether a cognitive process occurs in comprehension process or memory representation. The online characteristic of an inference is very important for understanding mental representation and its processes and designing natural language processing systems capable of human-like performance. Researchers found that instantiations of noun categories (Whitney, 1986), instrument inferences (Corbett \& Dosher, 1978; McKoon \& Ratcliff, 1981; Singer, 1979, 1980), causal consequence (Bloom, Fletcher, van den Broek, Reitz, \& Shapiro, 1990; McKoon \& Ratcliff, 1986, 1989; Potts, Keenan, \& Golding, 1988; Singer \& Ferreira, 1983), and state inferences (Seifert, 1990; Seifert et al., 1985) are generated offline. In contrast, some empirical evidence showed that referential inferences (Bever \& McElree, 1988; Dell, McKoon, \& Ratcliff, 1983; O’Brien, Duffy, \& Myers, 1986; Sanford \& Garrod, 1981), causal antecedent inferences (Magliano, Baggett, Johnson, \& Graesser, 1993), superordinate goal inferences (Long \& 
Golding, 1993; Long, Golding, \& Graesser, 1992; Long, Golding, Graesser, \& Clark, 1990), and protagonist's emotional inferences (Gernsbacher, Goldsmith, \& Robertson, 1992) are generated online. Many themes in literature are not explicitly stated in the form of an adage or a subject word. Themes are intentionally composed by writers and recovered by readers. In this regard, there is the question of whether the theme is activated online or offline. Is thematic inference, the activation of the theme of a narrative text, a fundamental component of the reading process?

Earlier research concentrated on the functions of the theme (e.g., Bisanz, Laporte, Vesonder, \& Voss, 1978; Dooling \& Lachman, 1971; Eamon, 1978-1979; Kozminsky, 1977; Pompi \& Lachman, 1967; Thorndyke, 1977). The studies on cognitive processes related to the formation rules of a theme such as deletion, generalization, and construction rules were done by Kintsch and van Dijk (1978; van Dijk \& Kintsch, 1983). Further explorations of the structure of themes emphasized the role of goals, plans, actions, and outcomes in thematic knowledge structure (Blanchard-Fields, 1996; Brewer \& Ohtsuka, 1988; Dorfman \& Brewer, 1994; Dyer, 1983; Jose, 1988; Jose \& Brewer, 1984; Lehnert, 1981; Schank, 1982; Schank \& Abelson, 1977). Recent studies of the generation of themes showed that readers are able to infer the themes of stories in classify tasks (Dorfman \& Brewer, 1994; Reiser, Black, \& Lehnert, 1985; Seifert, Dyer, \& Black, 1986) and thematic inference tasks (Kurtz \& Schober, 2001; Zhang \& Hoosain, 2001). However, there has been little experimental evidence about the online status of the generation of thematic inference. Currently, there are several models that are concerned with this topic. These models are often quite different in terms of their assumptions, and they are supported with different sets of empirical evidence.

A currently disputed model to account for inference generation during text comprehension is the minimalist hypothesis (McKoon \& Ratcliff, 1989, 1992). McKoon and Ratcliff (1992) proposed that only a few inferences are automatically encoded in narrative text reading. The minimalist hypothesis distinguishes inferences into strategic and automatic inferences. Strategic inferences are formed in pursuit of the reader' goals. For example, when readers want to obtain new information from the narrative text, they have specific goals and engage in strategic processing designed to achieve their goals. In this circumstance, strategic inferences are constructed. Automatic inferences (or online inferences) are generated in the absence of special strategies and carried out within a few hundred milliseconds (McKoon \& Ratcliff, 1986, 1989, 1992). The minimalist hypothesis claims that the only inferences automatically generated during reading are those that are based on quickly and easily available information and those that are required for local coherence of the text being read. According to the minimalist model, anaphoric references, case structure role assignments, and causal antecedents are the only types of inferences that are automatically generated because the three classes of inferences are needed to establish local coher- 
ence. Other inferences, including thematic inference, are only generated strategically but not automatically.

As an alternative viewpoint, a constructionist theory of inference generation (Graesser et al., 1994) points out that the reader attempts to construct a meaningful situation model that is coherent at both local and global levels and addresses the reader's goals; and explains why actions, events, and states are mentioned in the narrative text (Graesser \& Kreuz, 1993; Graesser et al., 1994). Unlike the minimalist hypothesis, the constructionist theory suggests that varied and many inferences are generated online during comprehension and makes distinctive predictions about which classes of inferences are generated online during text comprehension and which ones offline after text reading. There are a lot of empirical data lending support to the online status of several inferences at the local level predicted by the constructionist theory: referential inferences, case structure role assignment inferences, and causal antecedent inferences. Other studies demonstrated that some inferences at the global level are normally generated online, including superordinate goal inferences and protagonist emotion inferences. However, researchers pay less attention to the generation of thematic inferences. Thematic inferences are one of crucial inferences at the global level. Most of the information in a narrative text is usually organized around the theme of the text. Identification of the theme of a text is considered an important aspect of comprehension of the narrative text. At present, there are very few empirical studies of whether these thematic inferences are generated online in text reading, and existing empirical evidence testing thematic inferences has various problems.

A study with reference to thematic inferences was made by Seifert, McKoon, Abelson, and Ratcliff (1986). In their Experiments 1 and 2, participants read pairs of stories on each trial based on the same TAU or different TAUs and then made verification judgments on test sentences. Target test sentences that expressed the conclusion of a story appeared in four different priming conditions, namely, the priming sentence was the setup (i.e., the initiating circumstances of a story) from the same story, the setup from the other story, the conclusion from the other story that had the same TAU, or the conclusion from the other story that had different TAUs. The results of Experiment 1 showed that verification times for target test sentences in a pair of stories with the same theme were not faster than that for a pair of stories with different themes. In Experiment 2, experimental conditions were identical to those of Experiment 1 except that participants were encouraged to do strategic processing by asking them to think about the theme of a story during reading and rating similarities between stories after reading. It was found that verification time for the same TAU was faster than that for different TAUs. In Experiments 3 and 4, stories were presented one word at a time at the rate of $250 \mathrm{~ms}$, plus a $500 \mathrm{~ms}$ pause at the end of each sentence, and a 2,000 ms pause at the end of a story. In neither experiment was there any evidence of the activation of thematic information, even in Experiment 4 where 
specific instructions were given. To explain this, Seifert et al. added a prestudy task in Experiments 5 and 6 . In the prestudy phase, participants were required to read stories, answer questions about them, and write a summary of them. The results of both experiments showed that response times for test sentences indicating the same TAU were faster than those indicating different TAUs. Seifert et al. thought that participants might use strategies in reading the same stories (trying to remember them), and the prestudy led to better memory for the same stories so that it was easier for activation for test sentences in a study-test phase. In view of the aforementioned experiments, Seifert et al. suggested that thematic decoding is not automatic in text reading and depends on the reader's strategies.

In Seifert et al.'s (1986) study, they emphasized the instructions and ignored the reader's processing time for each word of the text. In their Experiments 1 and 2, stories averaged 80 words in length. Each story was presented for $20 \mathrm{~s}$ on the computer screen. This was equal to the rate of text presentation in which participants read one word for $250 \mathrm{~ms}$ at a time. This rate would not be conducive to the generation of thematic inferences when participants had no special strategy. However, participants with special goals might make long fixations and regressions for key words to construct the theme of a story. In Experiments 3 and 4, stories were presented 1 word at a time at the rate of $250 \mathrm{~ms}$. There was no evidence of the activation of thematic information, even in Experiment 4 where specific instructions were given. We consider that the results are due to the short presentation rate so that the readers could not attend to text representation and make thematic inference; although in both the experiments, there were $500 \mathrm{~ms}$ at the end of each sentence and 2,000 ms at the end of a story. Actually, additional time provided to participants amounted to only $77 \mathrm{~ms}$ and $25 \mathrm{~ms}$ respectively per word. Even if each word stayed on the screen after it was presented until the end of a story, 'new' words of a text were presented one by one on the screen, and such words demanded participants' attention more and made it less likely for regressions to previous text still staying on the screen. Therefore, participants made no thematic inferences even when instructions were given.

Another study related to generation of thematic inferences was done by Till, Mross, and Kintsch (1988), although their results are not directly relevant to the issue of whether thematic inferences are normally made during reading. In their experiments, participants read two-sentence texts presented by a rapid serial visual representation (RSVP) procedure and performed a lexical decision on target items that followed ambiguous prime words in the texts. When the target was a word, it was either an appropriate associate of the prime word, an appropriate thematic inference word generated by the text, an inappropriate associate of the prime word, or an inappropriate thematic inference word. Till et al. found that there was no difference between appropriate thematic inference words and inappropriate thematic inference words at short (200 ms to $400 \mathrm{~ms}$ ) stimulus onset asynchrony (SOA); but at longer (1,000 ms and 1,500 ms) SOA, thematic inference words were strongly 
facilitated relative to unrelated control words. However, Long, Oppy, and Seely (1994) found that skilled readers showed contextual effect on thematic words with the SOA of $500 \mathrm{~ms}$, using a procedure similar to Till et al.'s experiments.

In Till et al.'s (1988) study, we think that there were two methodological problems. One was that only some of the inference target words they investigated were thematic inference words. Others were inference words of different inference categories. For example, "The waitress smiled and said she would get off work soon. The young man decided to wait and left a big tip." The "date" presented after "tip" is a target word of thematic inference for this passage. The inference word, date, in the passage implies the superordinate goal. Till et al. did not clearly distinguish among inference categories in their target words. Another problem was that Till et al. only used the RSVP of $333 \mathrm{~ms}$ in their Experiment 1 and $300 \mathrm{~ms}$ in their Experiment 2. Many experiments suggested that readers process each word for approximately $350 \mathrm{~ms}$ to $400 \mathrm{~ms}$, allowing the text context to begin to make readers select an appropriate meaning of the word and then elaborate it into text representation (e.g., Kintsch \& Mross, 1985; Till et al., 1988). With the rate of displaying text in Till et al.'s experiments, it would be very difficult for participants to select and elaborate it into a text representation and construct the theme of a text.

In the previous studies on the generation of relevant thematic inferences, we have seen that major determinants of the generation of thematic inferences are readers' specific strategy (Seifert, McKoon, et al., 1986) and time course of inference generation (Till et al., 1988). On the whole, past studies lay particular emphasis on the effect of instructions or SOA. These investigations showed highly valuable as well as disparate findings. A common shortcoming of experimental designs in these studies is that the RSVP rate is not treated as an independent variable (Seifert, McKoon, et al., 1986; Till et al., 1988).

RSVP procedure allows participants to read words one by one in a text. RSVP rate reflects readers' processing time for each word of the text. SOA refers to the time between the onset of the final word in a sentence and the onset of a test item in the procedure. This delay time contributes to reavailability and integration for earlier information conveyed by the present sentence or the previous sentences. Our claim is that generation of thematic inference in narrative text reading depends on sufficient time of comprehension that includes the processing time for a word in a sentence and the integrating time for previous information at the end of a sentence. In this study, we compared the RSVP rate of $250 \mathrm{~ms}$ or $400 \mathrm{~ms}$ and the SOA of 250 $\mathrm{ms}, 400 \mathrm{~ms}$, or $600 \mathrm{~ms}$. We assume that the patterns of behavioral data under the RSVP of $400 \mathrm{~ms}$ with the SOA of $600 \mathrm{~ms}$ is different from those under the RSVP of $250 \mathrm{~ms}$ with the SOA of $250 \mathrm{~ms}$ or $400 \mathrm{~ms}$, because a shorter RSVP may not allow participants to have an adequate amount of time to comprehend critical words of a text and lead to a high amount of buffering near the end of a sentence. Meanwhile, a shorter SOA may limit readers to reaccess and integrate previous information of the text at the point when a test item is received. We predict that under the 
condition with the sufficient time of the RSVP of $400 \mathrm{~ms}$ and the SOA of $600 \mathrm{~ms}$, inferential contexts could facilitate the activation of a theme. In another words, readers are able to make thematic inference during narrative text reading; whereas, the shorter RSVP of $250 \mathrm{~ms}$ or the shorter SOA of $250 \mathrm{~ms}$ or $400 \mathrm{~ms}$ would limit construction of the theme of the text.

The objective of this study, by manipulating the RSVP rate combining with SOA, was to explore whether there is online generation of thematic inferences during narrative text comprehension. The designs of two experiments are based on the following basic assumption: If thematic inferences are generated online, it should be possible to show this by comparing response latencies of probe targets in inferential context with those in unrelated context. Furthermore, if response latencies of probe targets in inferential context are longer than or equal to those in unrelated context, thematic inferences are not generated online; if response times of probe targets in inferential context are shorter than those in unrelated context, thematic inferences are generated online. In this case, it is possible that thematic information is activated by the inferential context during text comprehension.

Before conducting the experiments, we used question-answering protocols to collect target words about narrative texts used in the studies. Participants were asked to read the narrative texts, clause by clause. Sufficient time was given for them to comprehend those texts. After reading each text, participants were asked to write down single words to express the theme of each text. Their answers constituted a collection of thematic inferences about those texts, assuming that an inference is made if readers have the prerequisite world knowledge, specific goal, and ample time of comprehension. Using the method, of course, we have not perfectly pinned down a word that completely reflects the theme of a narrative text. However, this verbal protocol indicates that potential thematic inferences are generated. To rigorously test whether thematic inferences are normally made online during reading, we employed a lexical decision task to proceed to do time-based behavioral measures in these experiments.

\section{EXPERIMENT 1}

The purpose of Experiment 1 was to investigate the online status of generation of thematic inferences for narrative texts and determine the time course in which thematic inferences are generated during text comprehension.

Many studies showed that context (e.g., Graesser \& Zwaan, 1995; Kintsch,1988), the RSVP rate (e.g., Magliano et al., 1993), and SOA (e.g., Till et al., 1988) influence inference generation during narrative text reading. In this experiment, context, RSVP rate, and SOA were manipulated. We used context of inference or unrelatedness; the RSVP rate of $250 \mathrm{~ms}$ or $400 \mathrm{~ms}$; and the SOA of 250 
$\mathrm{ms}, 400 \mathrm{~ms}$, or $600 \mathrm{~ms}$. We predicted that thematic inferences are generated online, and generation of thematic inferences is affected by the aforementioned factors.

\section{Method}

Participants. One hundred twenty-six 1st-year undergraduates of Beijing Agriculture College participated in this experiment. All had normal or corrected-to-normal vision. There were 21 participants in each cell.

Materials and experimental design. Twenty narrative texts were used in the experiment. Each text contained 12 sentences/clauses and one title. In each text, the first 3 sentences/clauses gave the background of the main event and the protagonist; the 4th sentence/clause indicated the central goal of the protagonist in the story; the 6th sentence/clause showed the plan of the protagonist to achieve the central goal; the 12th sentence/clause was the outcome of the text; the 5th sentence/clause and the sentences/clauses from the 7th to the 11th were about the states of the characters, the events, or the objects. Some of the texts were about life events, some depicted historical stories, and some were animal stories. Each text was a complete story describing episodes and implying a theme. All narrative texts were written by the experimenter, although some were based on stories in the literature.

Another 26 undergraduate students from Beijing Agriculture College who did not participate in the experiment were given a typed list of 38 texts in Chinese. They were asked to assess (a) the familiarity of the episodes for each text in terms of a 9-point rating scale ranging from 1 (very unfamiliar) to 9 (very familiar), (b) the coherence of the content of each text in terms of a 9-point rating scale ranging from 1 (very incoherent) to 9 (very coherent), and (c) the difficulty of understanding the theme for each text in terms of a 9-point rating scale ranging from 1 (understand very poorly) to 9 (understand very well). Instructions were also given in Chinese. On the basis of the students' evaluation of the familiarity of the episodes, the coherence of the content, and the difficulty of understanding the themes of the 38 texts, 20 texts were chosen and used in the experiment. The ratings of the 20 narrative texts for the familiarity of episodes averaged $2.3(S D=0.68)$. The ratings for the coherence of contents averaged $8.1(S D=0.97)$. The ratings for the difficulty of understanding the text themes averaged $3.4(S D=1.09)$. The 20 texts with high coherence of content, low familiarity of episodes, and moderate difficulty in understanding the theme satisfied the demand of our experiments: Texts with high coherence of content are conducive to constructing coherent meaning representation, texts with low familiarity of episodes and moderate difficulty in understanding the theme are suitable for the study of the generation of thematic inferences.

Target words for lexical decision tasks were collected in question-answering protocols from a different group of 18 respondents who did not participate in the 
experiment. They were asked to write five single-character words that came to mind and expressed the theme of each text after they had read each of the texts. These words produced by most participants were adopted as the experimental target words in the lexical decision task at the end of each text. The target words were content words. There were 6 verbs, 4 nouns, and 10 adjectives. In this experiment, these 20 target words were chosen as thematic target words in inference contexts. Meanwhile, the same target words were used as unrelated targets for other texts. Target words for the texts are presented in Appendix A. Other words and nonwords used for lexical decision tasks before the end of the texts were created by the experimenter.

After the computer presented the last character of each sentence/clause of a text, a word or nonword was presented for the lexical decision task. Nonwords are graphically possible characters that are not actually used in Chinese, created specially for this study. Words and nonwords were presented in a random order in a text.

Two of these narrative texts constituted two different contexts for the same target word. In the inferential context, the final word of a text was followed by a thematic inference word as target word. For the same word in the unrelated context, the final word of a text was followed by this irrelevant theme word as target word. For example,

\section{Ruixiang and Ferry-fare}

Ruixiang lived in a small town in the South (nonword)/He was always industrious and thrifty (nonword)/Ruixiang came across a river on his way one day (nonword)/He wanted to save the fare for the ferry boat (word)/The ferry boat was carrying people (nonword)/Ruixiang decided to swim across the river (word)/The river was deep and swift after the rain (nonword)/When he swam to the middle of the river (word)/The turbulent river rushed him away (nonword)/The ferry boat went to help him (nonword)/He swam struggling to the ferry boat (word)/He shouted not to collect the fare for the ferry (greedy-thematic inference word).

\section{Lion and Shepherd}

Lions are one of brutal wild animals (nonword)/They live in the woods and grass (nonword)/A lion had a pain in his leg which was hurt (nonword)/He wanted to repay whoever can help him (word)/The wounded leg made him walk with great difficulty (nonword)/He decided to ask the shepherd to help (word)/He walked lamely and found the shepherd (nonword)/The shepherd picked out the thorn in his paw (word)/The lion was soon caught and sent to the arena (nonword)/The opponent was the original shepherd (nonword)/The lion 
recognized the shepherd in the arena (word)/He affectionately licked the hands of shepherd (greedy-irrelevant thematic word).

The "Ruixiang and Ferry-fare" text provided the inferential context for the target word, greedy, whereas the "Lion and Shepherd" text provided an unrelated context for the same target word, greedy. Therefore, 20 story texts were paired with either a thematic inference word or an irrelevant word to form 40 experimental versions of the texts. To avoid that each participant read repeatedly the same text and the target word in the experiment, the 40 texts were divided into two text lists. There were 10 inferential texts and 10 unrelated texts in each text list, and the target words and the texts with the inferential contexts or the unrelated contexts were not repeated in the list presented to the same participant.

This study had an experimental design with three factors: the RSVP rate (250 ms vs. $400 \mathrm{~ms}$ ), examining how much time the reader needs to process each character of a text so as to generate online thematic inferences; the SOA (250 ms, 400 $\mathrm{ms}$, or $600 \mathrm{~ms}$ ), testing the minimal amount of time for construction of thematic encoding after a text is presented; and context condition (inferential and unrelated), providing information regarding whether textual contexts are related to thematic inferences. RSVP rate and SOA were between-subject variables, whereas context condition was a within-subjects variable. The dependent variable was response latency to target words. There were six groups of participants. Each participant read 20 texts in the two context conditions in a combination of the RSVP rate and SOA.

Procedure. Participants were randomly assigned to each text list with 20 texts. Participants were tested individually. They were asked to read carefully each narrative text, make a series of lexical decisions, and answer four comprehension questions after a narrative text. All the texts, words, and nonwords in lexical decision were presented on a computer screen; the comprehension questions were also on a computer screen to be answered by pressing a key. Participants were told that at first a brief clause was the title of each text.

One additional text was presented as a practice text for participants to familiarize with the experimental task. The 20 texts with inferential context or unrelated context in each text list were presented in random order.

The presentation procedure of a text was as follows: The trial began with presentation of the sentence, "Are you ready?" at the center of the screen. When participants pressed the key labeled " $y$ " on the keyboard, the text was presented one character at a time; each character presented in the center of a computer screen for $200 \mathrm{~ms}$ or $350 \mathrm{~ms}$, with a $50 \mathrm{~ms}$ blank interval between characters. The RSVP rate was the time of character presentation plus the blank interval between characters. Therefore, the RSVP rates were $250 \mathrm{~ms}$ or $400 \mathrm{~ms}$ in this experiment. The final character of each clause of the text was always presented for $200 \mathrm{~ms}$. Then there 
was a blank of either $50 \mathrm{~ms}, 200 \mathrm{~ms}$, or $400 \mathrm{~ms}$; a lexical decision test item followed it. The SOA was the time of the presentation of the last character in a sentence/clause plus the blank before the presentation of the test item for lexical decision. Therefore, the SOA was $250 \mathrm{~ms}, 400 \mathrm{~ms}$, or $600 \mathrm{~ms}$ in this experiment. The lexical decision item, as a character, was displayed at the same location on the screen, but it was surrounded by black squares (e.g., greedy $\square$ ). Participants were required to decide whether the test item was a word or nonword, as quickly and accurately as possible. If it was a word, participants pressed a key labeled "y." Otherwise, participants pressed the key labeled "n." The test item was then turned off. Then the next sentence/clause was presented character by character as before.

After participants had read each text and responded to the lexical decision tests, they were administered a comprehension test. Four statements were presented one at a time on the screen. Participants decided whether the statement was correct for the text. If the statement was consistent with the meaning of the text content, participants pressed the y key, and if the statement was not consistent with the text content, participants pressed the $\mathrm{n}$ key. Participants' responses were recorded. We were only interested in response times for the target words at the end of the texts. Items for lexical decision at the end of earlier sentences/clauses were fillers.

\section{Results}

The response latency data for the incorrect responses to the target word in the lexical decision task were excluded from the analysis. All response latencies deviating more than 3 standard deviations from the mean were deleted. Errors and outliers constituted $2 \%$ of the data. The mean comprehension score of the texts were $97 \%$ correct. The results of this experiment are shown in Table 1, in terms of the response latencies as a function of RSVP rate, SOA, and context condition. $F$ values are reported by participants $(F 1)$ and items $(F 2)$.

TABLE 1

Mean Response Latencies (in Milliseconds) in Experiment 1 as a Function of RSVP, SOA, and Context

\begin{tabular}{lcccccc}
\hline & & \multicolumn{2}{c}{ Inferential Context } & & \multicolumn{2}{c}{ Unrelated Context } \\
RSVP & SOA & $M$ & & & & \\
\hline 250 & 250 & 883.62 & 195.53 & & 924.07 & 212.45 \\
250 & 400 & 832.06 & 255.05 & & 863.46 & 248.53 \\
250 & 600 & 807.15 & 114.98 & & 840.93 & 113.94 \\
400 & 250 & 810.04 & 123.68 & & 889.81 & 173.96 \\
400 & 400 & 788.06 & 144.91 & & 870.05 & 173.49 \\
400 & 600 & 653.57 & 198.13 & & 794.43 & 135.35 \\
\hline
\end{tabular}

Note. $\quad \mathrm{RSVP}=$ rapid serial visual presentation; $\mathrm{SOA}=$ stimulus onset asynchrony. 
A $2($ RSVP rate $) \times 3(\mathrm{SOA}) \times 2$ (context) repeated measures analysis of variance (ANOVA) was performed on response latencies of target words. There was a significant main effect of RSVP rate, $F 1(1,120)=4.02, p<.05 ; F 2(1,19)=8.74, p$ $<.01$. There was a significant main effect of SOA, $F 1(2,120)=4.37, p<.05 ; F 2(2$, $38)=3.30, p<.05$. There was also a significant main effect of context condition, $F 1(1,120)=22.01, p<.001 ; F 2(1,19)=12.34, p<.005$.

The RSVP Rate $\times$ Context interaction yielded a significant effect on response latency, $F 1(1,120)=5.12, p<.05 ; F 2(1,19)=4.47, p<.05$. We conducted further post hoc comparisons and found that the facilitative effect of context condition on thematic inferences was significant only for stimulus presentation of the RSVP rate of $400 \mathrm{~ms}(750 \mathrm{~ms}$ vs. $851 \mathrm{~ms}): p<.01$ by participants, and $p<.05$ by items. It was not significant for stimulus presentation of the RSVP rate of $250 \mathrm{~ms}(840 \mathrm{~ms}$ vs. $876 \mathrm{~ms}$ ): $p>.10$ by participants, and $p>.50$ by items. However, the SOA $\times$ Context interaction was not significant by participants or by items, $F 1(2,120)=$ $0.44, p=.64 ; F 2(2,38)=1.72, p=.19$.

The interaction of RSVP Rate $\times$ SOA $\times$ Context was not significant, $F 1(2,120)$ $=0.52, p=.59 ; F 2(2,38)=0.87, p=.42$. Comparing the different effects among the RSVP rate and the SOA was one of the purposes of this experiment, so planned comparisons were conducted across participants and items and showed that the facilitative effect of inferential contexts was significant only for the RSVP rate of $400 \mathrm{~ms}$ and the SOA of $600 \mathrm{~ms}$ (653 ms vs. $794 \mathrm{~ms}): p<.01$ by participants, and $p$ $<.01$ by items. It was not significant for the RSVP rate of $400 \mathrm{~ms}$ and the SOA of $250 \mathrm{~ms}$ ( $810 \mathrm{~ms}$ vs. $889 \mathrm{~ms}$ ): $p>.10$ by participants, and $p>.10$ by items. It was also not significant for the RSVP rate of $400 \mathrm{~ms}$ and the SOA of $400 \mathrm{~ms}$ (788 ms vs. $870 \mathrm{~ms}$ ): $p>.10$ by participants, and $p>.05$ by items. When the RSVP rate was $250 \mathrm{~ms}$, the SOA was $250 \mathrm{~ms}, 400 \mathrm{~ms}$, or $600 \mathrm{~ms}$, respectively; there were no facilitative effects of inferential context on the target words (883 ms vs. $924 \mathrm{~ms}$, $832 \mathrm{~ms}$ vs. $863 \mathrm{~ms}$, and $807 \mathrm{~ms}$ vs. $840 \mathrm{~ms}$, respectively): by participants, $p$ > .10; and by items, $p>.10$.

\section{Discussion}

The important finding of this experiment is that readers generated thematic inferences online when the SOA was $600 \mathrm{~ms}$ with the RSVP rate of $400 \mathrm{~ms}$. This result is different from that of Till et al. (1988). In their experiments, the prime-target SOA was $200 \mathrm{~ms}, 300 \mathrm{~ms}, 400 \mathrm{~ms}, 500 \mathrm{~ms}, 1,000 \mathrm{~ms}$, or 1,500 ms with the RSVP rate of $300 \mathrm{~ms}$, or the SOA was $333 \mathrm{~ms}$ or $1,000 \mathrm{~ms}$ with the RSVP rate of $333 \mathrm{~ms}$. They found that there was no difference between appropriate thematic inference words and inappropriate thematic inference words at short SOA $(200 \mathrm{~ms}, 300 \mathrm{~ms}$, $400 \mathrm{~ms}, 500 \mathrm{~ms})$; at longer SOA (1,000 ms and 1,500 ms), identification of thematic inference words was strongly facilitated relative to unrelated control words. In a way, some of their results were consistent with the results of our experiment, 
namely, that there was absence of facilitative effect of text for the shorter SOA of $250 \mathrm{~ms}$ and $400 \mathrm{~ms}$ in our experiment also. However, we found facilitative effect on thematic inferences with the SOA of only $600 \mathrm{~ms}$ with the RSVP rate of $400 \mathrm{~ms}$. This is close to the result of Long et al. (1994): Skilled readers can make thematic inferences at the SOA of $500 \mathrm{~ms}$. We think that the SOA of 1,000 ms and 1,500 ms may not be necessary for thematic inference when the text was presented at the RSVP rate of $400 \mathrm{~ms}$. In Till et al.'s study, the main problem was that they used the RSVP rate of $300 \mathrm{~ms}$ or $333 \mathrm{~ms}$ with negligible off time between words. Participants may not fully process the words and integrate them into mental representation of a text during reading. This would have an impact on the normal generation of thematic inferences. Understanding a theme in this situation needs longer SOA to complete construction of the theme of a text. Therefore, we think that the RSVP rate of $400 \mathrm{~ms}$ and the SOA of $600 \mathrm{~ms}$ are very important conditions for online generation of thematic inferences during text comprehension, at least for Chinese.

This result is not incompatible with the eye-tracking studies. The RSVP rate of $400 \mathrm{~ms}$ in our experiment consisted of $350 \mathrm{~ms}$ for actual word display and $50 \mathrm{~ms}$ blank interval between characters. The eye-tracking recordings show that there are saccades, fixations, and regressions in reading. Although the mean fixation lasts about $250 \mathrm{~ms}$, there is a perceptual span for about 3 to 4 letter spaces to the left of fixation and about 14 to 15 letter spaces to the right of fixation when the reader fixates at an English word (e.g., McConkie \& Rayner, 1975, 1976; Rayner, Well, \& Pollatsek, 1980). This indicates that processing time per word may actually exceed $250 \mathrm{~ms}$. For Chinese, comparable eye movement data have been reported (Yang \& McConkie, 1999). Also, there are longer fixation times of about $1,000 \mathrm{~ms}$ for important or difficult words of a text. The eye-movement data were collected from experiments on comprehension and memory for information stated explicitly in the text. Thematic inferences are based on assuming, verifying, and revising processes for information stated explicitly and implicitly in the text; integrating major chunks of the text; and conveying the main point of the text. This information processing at deeper semantic level may need a process time amounting to the RSVP rate of $400 \mathrm{~ms}$ during text reading.

This finding of the online generation of thematic inferences in our study is different from Seifert, McKoon, et al.'s (1986) results. In their Experiments 1 and 2, they found that thematic inferences were made under specific instruction, and no thematic inferences were made when there was no specific instruction. In their Experiments 3 and 4, the results showed that there was no activation of thematic information, even in Experiment 4 where specific instructions were given. According to our experimental results, when the RSVP rate and the SOA of stimulus presentation times reach $400 \mathrm{~ms}$ and $600 \mathrm{~ms}$, respectively, thematic inferences of narrative text are generated online during reading. In Seifert, McKoon, et al.'s Experiments 3 and 4, presentation time for each word was short at $400 \mathrm{~ms}$ per word. Therefore, thematic inference was not constructed even when specific instruction 
was given. This may also be the reason for different results between Experiments 2 and 4. In their Experiment 2, readers could allocate time to read a text with special strategy and had enough time to elaborate important words into a text representation and construct the theme of a text. However, in their Experiment 4, readers did not have enough time to integrate the meaning of the words into a representation and generate the theme of a story. In a way, Seifert, McKoon, et al. emphasized the reader's strategies and ignored the factor of the processing time for each word individually.

\section{EXPERIMENT 2}

The main purpose of Experiment 2 was to further investigate the online status of the generation of thematic inferences during text comprehension, by analyzing the effect of contexts on target words at different locations in a text. The second aim was to explore whether there is any effect of the consistency between the protagonist's goal and the outcome of a text on thematic inference during reading.

The text comprehension model (van Dijk \& Kintsch, 1983) predicted that the reader needs not wait until the end of a text or whole discourse before being able to infer what the text is about. We predict that thematic inference is generated halfway through a text, and the generation of thematic inference is affected by consistency between the protagonist's goal and the outcome of a text.

\section{Method}

Participants. Thirty-two undergraduate 2nd-year students of Beijing Agriculture College participated in the experiment. The participants were randomly assigned to two groups. All had normal or corrected-to-normal vision.

Materials and experimental design. The 20 narrative texts in Experiment 1 were used in this experiment. Due to the additional variable of target item at the middle of a text, we added 20 unrelated target items in this experiment. The two kinds of target words (thematic inferential and unrelated) were matched in terms of word frequency according to the Modern Chinese Frequency Dictionary (1986). Their composition in terms of word class was identical: 6 verbs, 4 nouns, and 10 adjectives. The target words are presented in Appendix B.

For the condition of target items appearing at the end of a text, each of the narrative texts constituted two different context conditions. When the final character of a text was followed by a thematic inference word (for performing a lexical decision task), the text was the inferential context for this target word. When the final character of a text was followed by an irrelevant target word, the text was the unrelated context for this target word. In addition, the target items for lexical decision task 
following the end of the sixth sentence/clause in a text were also investigated in this experiment (i.e., the partial contents of a text constituted an unrelated context or a thematic inferential context for the target item halfway through the text). Therefore, the same story text appeared in one text list with an unrelated target word by the middle of the text and provided an inferential context for another target word at the end of the text. For example,

\section{Ruixiang and Ferry-fare}

Ruixiang lived in a small town in the South (nonword)/He was always industrious and thrifty (nonword)/Ruixiang came across a river on his way one day (nonword)/He wanted to save the fare for the ferry boat (word)/The ferry boat was carrying people (nonword)/Ruixiang decided to swim across the river (melting-irrelevant thematic word)/The river was deep and swift after the rain (nonword)/When he swam to the middle of the river (word)/The turbulent river rushed him away (nonword)/The ferry boat went to help him (nonword)/He swam struggling to the ferry boat (word)/He shouted not to collect the fare for the ferry (greedy-thematic inference word).

The "Ruixiang and Ferry-fare" text provided the inferential context for the last target word, greedy, but the partial textual content of the beginning six sentences/clauses provided an unrelated context for the middle target word, melting.

The same story text appeared in a second text list, providing partial inferential context for a related target word halfway through the text (greedy) and an unrelated context for another target word at the end of the text (melting). For example,

\section{Ruixiang and Ferry-fare}

Ruixiang lived in a small town in the South (nonword)/He was always industrious and thrifty (nonword)/Ruixiang came across a river on his way one day (nonword)/He wanted to save the fare for the ferry boat (word)/The ferry boat was carrying people (nonword)/Ruixiang decided to swim across the river (greedy - thematic inference word)/The river was deep and swift after the rain (nonword)/When he swam to the middle of the river (word)/The turbulent river rushed him away (nonword)/The ferry boat went to help him (nonword)/He swam struggling to the ferry boat (word)/He shouted not to collect the fare for the ferry (melting-irrelevant thematic word).

The same text provided an unrelated context for the last target word, melting, but the textual content of the beginning six clauses provided partial inferential context for the midway target word, greedy. We divided these texts and target words into two text lists, to avoid each participant having to repeatedly read the same text and target word in the experiment. In each text list, there were 10 inferential contexts 
and 10 unrelated contexts at the end of the texts and also 10 partial inferential contexts and 10 partial unrelated contexts at the middle of the texts.

We controlled another independent variable in the experimental materials, namely, the consistency between the protagonist's goal and the outcome of the texts. In some texts, the goal of the protagonist was consistent with the outcome of a text, whereas in other texts the protagonist's goal was inconsistent with the outcome of a text. For example,

\section{Wang Yang and Fire}

Wang Yang was the eldest son of the Wang's in a village (non-word)/One day his parents went to town for shopping (nonword)/Black smoke rose from the top of the kitchen during his cooking (nonword)/Wang Yang wanted to put out the small fire above (word)/Wang Yang was a person of short stature (nonword)/He decided to borrow a ladder from the neighbor (simple-irrelevant word)/He came to the home of the neighbor who had a ladder (nonword)/The owner of the ladder said hello to him with civility (word)/The host served a cup of hot tea (nonword)/After Wang Yang had the cup of hot tea (nonword)/He shouldered the ladder to go back to the gate of his house (word)/Raging fire had already embraced his house (tardy-thematic inference word).

In this text, Wang Yang's goal was that he wanted to put out a small fire in his house, but the outcome of this text was that the raging fire had already embraced his house. From the outcome of the text, we know that later developments turned against the initial goal of the protagonist. In this case, the outcome of the text was inconsistent with the protagonist's goal. However, the outcomes of the texts were consistent with the protagonists' goals in the other kind of texts, such as in "Lion and Shepherd" and "Ruixiang and Ferry-Fare." The 20 texts in this experiment contained 10 texts in which the outcomes of the text were consistent with the protagonists' goals and 10 texts in which the outcomes of the text were inconsistent with the protagonists' goals; the two kinds of texts were presented in a random order in each of two text lists.

Narrative texts were presented at the RSVP rate of $400 \mathrm{~ms}$ and the SOA of 600 ms. Participants were required to perform lexical decision tasks for test items following the final character of each sentence/clause of the texts. We were interested in the responses to the target words at the end of the whole texts and at the middle of the texts. The items for lexical decision tasks at the end of other sentences/clauses were just fillers.

Procedure. Participants were randomly assigned to each of two groups to be presented one of the text lists. Participants were asked to carefully read each narra- 
tive text and make a series of lexical decisions. After reading each text, there were four comprehension questions.

\section{Results}

The dependent measure of this experiment was response latency in the lexical decision task for two contexts. In this experimental design, thematic target words and the corresponding unrelated target words were placed at the end and the middle of texts; therefore, we focus on the analyses of the data for correctly identified target words at these two locations only. Mean comprehension scores for the texts were $95 \%$ correct. The response latency data for texts with incorrect responses were excluded from the analysis. All response latencies deviating more than 3 standard deviations from the mean were deleted. Errors and outliers constituted $3 \%$ of the data.

For the data from the end of narrative texts, a paired-samples $t$ test was performed for response latencies for target words at the end of the texts. There was a significant effect of context, $t 1(31)=7.01, p<.001$, by participants, and $t 2(19)=$ $3.35, p<.005$, by items.

Our main interest in Experiment 2 is for target words at the middle of the texts. Table 2 shows the data from the middle of narrative texts, in terms of response latencies as a function of context and consistency between goal and outcome. We performed a 2 (context condition) $\times 2$ (consistency) repeated measures ANOVA for response latencies for target words at the middle of texts. There was a significant main effect of context, $F 1(1,31)=16.12, p<.001$, and $F 2(1,18)=4.54, p<$ .05 . There was also a main effect of consistency, $F 1(1,31)=15.57, p<.001$, and $F 2(1,18)=5.51, p<.05$. The Context $\times$ Consistency interaction was significant, $F 1(1,31)=6.56, p<.05$, and $F 2(1,18)=4.96, p<.05$. For the Context $\times$ Consistency interaction, further post hoc comparisons showed that partially inferential contexts facilitated identification of thematic target word, compared to unrelated contexts, when the outcome of a text was consistent with the protagonist's goal (662 ms vs. $877 \mathrm{~ms}$ ): $p<.05$ by participants, and $p<.05$ by items. However, partially inferential contexts did not affect identification of thematic target word,

TABLE 2

Mean Response Latencies (in Milliseconds) at the Middle of Texts in Experiment 2 as a Function of Context and Consistency

\begin{tabular}{|c|c|c|c|c|}
\hline \multirow[b]{2}{*}{ Consistency } & \multicolumn{2}{|c|}{ Inferential Context } & \multicolumn{2}{|c|}{ Unrelated Context } \\
\hline & $M$ & $S D$ & $M$ & $S D$ \\
\hline Consistent & 662.03 & 224.32 & 877.70 & 370.07 \\
\hline Inconsistent & 853.25 & 344.36 & 891.63 & 287.00 \\
\hline
\end{tabular}


compared to unrelated contexts ( $853 \mathrm{~ms}$ vs. $891 \mathrm{~ms}): p>.50$ by participants and by items when the outcome of a text was inconsistent with the protagonist's goal.

\section{Discussion}

The result of this experiment indicated that participants constructed the theme of each text at the end of the text at the RSVP rate of $400 \mathrm{~ms}$ and the SOA of $600 \mathrm{~ms}$, which replicated the results of Experiment 1. An important finding in this experiment was that significant facilitative effects of inferential context on thematic words were obtained at the middle of some texts. In other words, thematic inference was generated although the readers had only read the partial contents of a narrative text. This suggested that global coherence is established to an extent to which relevant constituents of a text can be linked together by an overarching theme, even halfway through the texts. This result is consistent with van Dijk and Kintsch's (1983) prediction that the theme of a text may also be inferred on the basis of incomplete information:

A language user need not wait until the end of a paragraph, chapter, or whole discourse before being able to infer what the text or the text fragment is about, globally speaking. In other words, it is plausible that with a minimum of textual information from the first propositions, the language user will make guesses about such a topic. (p. 15)

The finding of this study supports our research assumption: Thematic inference is reconstruction of the central idea that is not stated explicitly in a narrative text by assuming, verifying, and revising processes during text reading. When readers comprehend the relevant information of the text partially and make the possible expectation of the outcome, a theme of the text is assumed. As available information increases with continued text reading, the possible theme will be verified. If it is consistent with information given later, this theme is maintained in working memory. If it is inconsistent with information given later, this preliminary theme is revised into a more appropriate theme to express the text. These processes are carried out until the end of the text. For example, after participants reading the earlier six sentences/clauses in the text of "Ruixiang and Ferry-Fare," they integrated contents of the text and constructed a preliminary theme based on the partial text and their expectation. Therefore, they comprehended that Ruixiang wanted to swim across a river to save the ferry fare and generated a theme that the greedy seek money more than life. Latter contents of this text were developed along the theme until the end of the text. Stated differently, there was no conflict between the protagonist's goal and the outcome of the text. Therefore, the preliminary theme based on the partial text is also the theme of all of the text. However, participants might generate a theme that Wang Yang put out the fire in an appropriate way after they 
read the beginning six sentences/clauses in the text of "Wang Yang and Fire." As contents of the text were unfolded, readers got further information that Wang Yang had a cup of tea and did not hurry up with borrowing a ladder. The preliminary theme of his putting out the fire in an appropriate way would be substituted with another theme that important matters should not be handed tardily. In other words, latter information as text developed was inconsistent with the protagonist's goal. This conflict between the outcome of the text and the protagonist's goal made readers revise the preliminary theme and reconstruct a new theme. In this case, the participants, based on partial contents of the text and the expectation, could not construct the correct theme for all the text. Therefore, when participants read only the earlier six sentences/clauses, they might not think that the test item "tardy" was related to the theme of the story; resulting in longer response latency.

Therefore, when earlier parts of a text were closely related to the theme of the text and latter parts of the text were consistent with the previous context, participants might grasp relevant information of the earlier part of the text and make correct thematic inference. Important information provided from partial contents of a text can fully trigger thematic inference. Later information compatible with the previous contents plays a small role for constructing the theme of a text. In this situation, we observed the reliable presence of thematic inference in the middle of inferential context when the reader makes correct assumption or expectation of the outcome in a story (there was a consistency between the outcome of a text and the previously stated protagonist's goal).

This experimental finding of the online status of the generation of thematic inferences in understanding earlier parts of a text matches our experience in daily life. When a person tells us a plot about events, we could often understand the main point of the plot although we know only the partial contents of the plot. In other words, we certainly do not need total information to grasp the main theme in the communication. The given explicit partial contents of events from the speaker and the knowledge-based information retrieved by the listener may activate or construct the overarching theme of a plot. The latter information in communication may be used to support or complement the assumed theme of discourse. However, when the latter information conflicts with the former assumed theme, the listener needs to revise or reconstruct a more appropriate theme according to the remaining information of the discourse.

\section{GENERAL DISCUSSION}

The results of the study demonstrated that thematic inferences are generated online during narrative text comprehension under the condition in which narrative texts are presented at the RSVP rate of $400 \mathrm{~ms}$ and the SOA of $600 \mathrm{~ms}$. More precisely, there is a threshold of about the RSVP of $400 \mathrm{~ms}$ and the SOA of $600 \mathrm{~ms}$. When 
readers go through a narrative text, if it equals to or exceeds this threshold, themes are generated online. In addition, we further observed that when the protagonist's goal was consistent with the outcome of the text, thematic inferences are generated at the middle of the text during reading. The results of this study reveal that global theme of a narrative text is a fundamental component of mental representation of the text in reading. It should be noted that although our data are obtained with Chinese texts, work on eye movement during reading of Chinese indicates that text reading speed for Chinese are comparable to English (Yang \& McConkie, 1999).

Past studies demonstrating evidence for the generation of thematic inferences did not play particular attention to the RSVP rate, resulting in different conclusions. One aspect that was emphasized was the influence of processing strategies on thematic inference (Seifert, McKoon, et al., 1986). The other aspect emphasized was the functions of the SOA of stimulus presentation for thematic inference (Till et al., 1988). These studies of SOA and strategies lead to some researchers holding that thematic inferences may not be generated online during natural reading. However, from another angle, if we attend to the RSVP rate of stimulus presentation and let participants have the necessary time to integrate central information during reading processes, we can get a very different picture; namely, that thematic inferences are generated online during narrative text comprehension.

The results of the study are relevant to both the minimalist hypothesis and the constructionist theory of inference generation. Most researchers agree that readers make inferences online to establish local coherence during reading (Graesser et al., 1994; McKoon \& Ratcliff, 1992; Singer, Graesser, \& Trabasso, 1994). However, the extent to which readers make inferences to achieve global coherence is controversial. Our experiment findings are inconsistent with McKoon and Ratcliff's (1992) minimalist hypothesis: Inferences are constructed when there is a local coherence break or when information is readily available and when readers have specific strategies to read text. In our experiments, the readers comprehended the texts without the demand of strategies of thematic processing. According to the minimalist point of view, thematic inferences ought not to be generated online in text reading. In addition, our experimental narrative texts were of middle level of difficulty of thematic understanding, based on the pretest evaluation on the 9-point scale. Therefore, according to the minimalist hypothesis, these themes of narrative texts should not have been made readily available. Failing to confirm McKoon and Ratcliff's (1992) hypothesis, the results of our experiments suggested that thematic inference is normally generated when readers read the texts with the RSVP rate of $400 \mathrm{~ms}$ and the SOA of $600 \mathrm{~ms}$.

These findings provide robust support for the global coherence assumption of inference generation in the constructionist model (Graesser et al., 1994), which asserts the importance of overarching thematic information in constructing text meaning representation. Over the past two decades, some models of text comprehension involved analyses of global coherence (e.g., Gernsbacher, 1990; van Dijk 
\& Kintsch, 1983). Recently, the constructionist theory (Graesser et al., 1994; Singer et al., 1994) integrated the construction-integration model (Kintsch, 1988), collaborative activation-based production system model (Just \& Carpenter, 1992), and the structure building framework (Gernsbacher, 1990) and further emphasized the significance of the global coherence in meaning representation.

The reader attempts to construct a coherent meaning representation that occurs not only at local levels but also at global levels. Establishment of global coherence of text meaning representation is more important for readers. Local coherence is an initial stage of comprehension. Readers cannot stop at this level. The reader attempts to integrate crucial information in the text into a theme that captures major aspects of text content. Thematic inferences, as the headrope of a fishing net, is overarching all of the text rather than remaining in an isolated and initial state. Otherwise, without thematic inferences to integrate these individual parts together, comprehension of a text is just like comprehension of a sentence of individual words without the complete meaning of the sentence. Our findings and other studies of superordinate goal inference (Graesser, Haberlandt, \& Koizumi, 1987; Long \& Golding, 1993; Long et al., 1992; Long et al., 1990) and protagonist emotion inference (Gernsbacher, 1995; Gernsbacher et al., 1992) reveal online occurrence of several global coherence inferences; those findings provide robust support for the constructionist theory of inference generation that argues that global coherence inferences play important roles in text representation during reading.

\section{ACKNOWLEDGMENTS}

We would like to thank Arthur Graesser and three anonymous reviewers for their constructive comments and suggestions. We are grateful to Kathryn Bock, Paul van den Broek, Jon Magliano, and Paul Whitney for their valuable suggestions on an earlier version of this article.

\section{REFERENCES}

Balota, D. A., Flores d'Arcais, G. B., \& Rayner, K. (1990). Comprehension processes in reading. Hillsdale, NJ: Lawrence Erlbaum Associates, Inc.

Bever, T. G., \& McElree, B. (1988). Empty categories access their antecedents during comprehension. Linguistic Inquiry, 19, 35-44.

Bisanz, G. L., Laporte, R. E., Vesonder, G. T., \& Voss, J. F. (1978). On the presentation of prose: New dimensions. Journal of Verbal Learning and Verbal Behavior, 17, 337-357.

Blanchard-Fields, F. (1996). Causal attributions across the adult life span: The influence of social schemas, life context, and domain specificity. Applied Cognitive Psychology, 10, 137-146.

Bloom, C. P., Fletcher, C. R., van den Broek, P., Reitz, L., \& Shapiro, B. P. (1990). An online assessment of causal reasoning during comprehension. Memory \& Cognition, 18, 65-71. 
Bower, G. H., Black, J. B., \& Turner, T. G. (1979). Scripts in memory for text. Cognitive Psychology, 11, 177-220.

Bransford J. D., \& Johnson, M. K. (1972). Contextual prerequisites for understanding: Some investigations of comprehension and recall. Journal of Verbal Learning and Verbal Behavior, 11, 717-726.

Brewer, W. F., \& Ohtsuka, K. (1988). Story structure, characterization, just world organization, and reader affect in American and Hungarian short stories. Poetics, 17, 395-415.

Corbett, A. T., \& Dosher, B. A. (1978). Instrument inferences in sentence encoding. Journal of Verbal and Verbal Behavior, 17, 479-491.

Dell, G., McKoon, G., \& Ratcliff, R. (1983). The activation of antecedent information during the processing of anaphoric reference in reading. Journal of Verbal Learning and Verbal Behavior, 22, $121-132$.

Dooling, D. J., \& Lachman, R. (1971). Effects of comprehension on retention of prose. Journal of Experimental Psychology, 88, 216-222.

Dorfman, M. H., \& Brewer, W. F. (1994). Understanding the points of fables. Discourse Processes, 17, $105-129$.

Dyer, M. G. (1983). In-depth understanding: A computer model of integrated processing for narrative comprehension. Cambridge, MA: MIT Press.

Eamon, D. B. (1978-1979). Selection and recall of topical information in prose by better and poorer readers. Reading Research Quarterly, 14, 244-257.

Gernsbacher, M. A. (1990). Language comprehension as structure building. Hillsdale, NJ: Lawrence Erlbaum Associates, Inc.

Gernsbacher, M. A. (1995). Activation knowledge of fictional characters' emotional states. In C. A. Weaver, III, S. Mnnes, \& C. R. Fletcher (Eds.), Discourse comprehension: Essays in honor of Walter Kintsch (pp. 141-156). Hillsdale, NJ: Lawrence Erlbaum Associates, Inc.

Gernsbacher, M. A., Goldsmith, H. H., \& Robertson, R. R. (1992). Do readers mentally represent character's emotional states? Cognition and Emotion, 6, 89-112.

Graesser, A. C., \& Bower, G. H. (Eds.). (1990). Inferences and text comprehension. San Diego, CA: Academic.

Graesser, A. C., Golding, J. M., \& Long, D. L. (1991). Narrative representation and comprehension. In R. Barr, M. L. Kamil, P. Mosenthal, \& P. D. Pearson (Eds.), Handbook of reading research (pp. 191-205). White Plains, NY: Longman.

Graesser, A. C., Gordon, S. E., \& Sawyer, J. D.(1979). Recognition memory for typical and atypical actions in scripted activities: Tests of a script pointer plus tag hypothesis. Journal of Verbal Learning and Verbal Behavior, 18, 319-322.

Graesser, A. C., Haberlandt, K., \& Koizumi, D. (1987). How is reading time influenced by knowledge-based inferences and world knowledge? In B. K. Britton \& S. M. Glynn (Eds.), Executive control processes in reading (pp. 217-251). Hillsdale, NJ: Lawrence Erlbaum Associates, Inc.

Graesser, A. C., \& Kreuz, R. J. (1993). A theory of inference generation during text comprehension. Discourse Processes, 16, 145-160.

Graesser, A. C., \& Nakamura, G. V. (1982). The impact of schemas on comprehension and memory. In G. H. Bower (Eds.), The psychology of learning and motivation (Vol. 16, pp. 60-110). New York: Academic.

Graesser, A. C., Pomeroy, V. J., \& Craig, S. D. (2002). Psychological and computational research on theme comprehension. In M. Louwerse \& W. Van Peer (Eds.), Thematics: Interdisciplinary studies (pp. 19-34) Amsterdam: Benjamins.

Graesser, A. C., Singer, M., \& Trabasso, T. (1994). Constructing inferences during narrative text comprehension. Psychological Review, 3, 371-395.

Graesser, A. C., \& Zwaan, R. A. (1995). Inference generation and the construction of situation models. In C. A. Weaver, III, S. Mannes, \& C. R. Fletcher (Eds.), Discourse comprehension: Essays in honor of Walter Kintsch (pp. 117-139). Hillsdale, NJ: Lawrence Erlbaum Associates, Inc. 
Jose, P. E. (1988). Liking of plan-based stories: The role of goal importance and goal attainment difficulty. Discourse Processes, 11, 261-273.

Jose, P. E., \& Brewer, F. B. (1984). Development of story liking: Character identification, suspense, and outcome resolution. Developmental Psychology, 20, 911-924.

Just, M. A., \& Carpenter, P. A. (1992). A capacity theory of comprehension: Individual differences in working memory. Psychological Review, 99, 122-149.

Kintsch, W. (1988). The role of knowledge in discourse comprehension: A constructive-integration model. Psychological Review, 95, 163-182.

Kintsch, W. (1993). Information accretion and reduction in text processing: Inferences. Discourse Processes, 16, 193-202.

Kintsch, W., \& Mross, E. F. (1985). Context effects in word identification. Journal of Memory and Language, 24, 336-349.

Kintsch, W., \& van Dijk, T. A. (1978). Toward a model of text comprehension and production. Psychological Review, 85, 363-394.

Kozminsky, E. (1977). Altering comprehension: The effect of biasing titles on text comprehension. Memory \& Cognition, 5, 482-490.

Kurtz, V., \& Schober, M. F. (2001). Readers' varying interpretations of theme in short fiction. Poetics, 29, 139-166.

Lehnert, W. G. (1981). Plot units and narrative summarization. Cognitive Science, 5, $283-331$.

Long, D. L., \& Golding, J. M. (1993). Superordinate goal inferences: Are they automatically generated during comprehension? Discourse Processes, 16, 55-73.

Long, D. L., Golding. J. M., \& Graesser, A. C. (1992). A test of the on-line status of goal-related inferences. Journal of Memory and Language, 31, 634-647.

Long, D. L., Golding, J. M., Graesser, A. C., \& Clark, L. F. (1990). Goal, event, and state inferences: An investigation of inference generation during story comprehension. In A. C. Graesser \& G. H. Bower (Eds.), The psychology of learning and motivation: Inferences and text comprehension (pp. 89-107). New York: Academic.

Long, D. L., Oppy, B. J., \& Seely, M. R. (1994). Individual differences in the time course of inferential processing. Journal of Experimental Psychology: Learning, Memory, and Cognition, 20, $1456-1470$.

Magliano, J. P., Baggett, W. B., Johnson, B. K., \& Graesser, A. C. (1993). The time course of generating causal antecedent and causal consequence inferences. Discourse Processes, 16, 35-53.

Magliano, J. P., \& Graesser, A. C. (1991). A three-pronged method for studying inference generation in literary text. Poetics, 20, 193-232.

McConkie, G. W., \& Rayner, K. (1975). The span of the effective stimulus during an eye fixation in reading. Perception \& Psychophysics, 17, 578-586.

McConkie, G. W., \& Rayner, K. (1976). Asymmetry of the perceptual span in reading. Bulletin of the Psychonomic Society, 8, 365-368.

McKoon, G., \& Ratcliff, R. (1981). The comprehension processes and memory structures involved in instrumental inferences. Journal of Verbal Learning and Verbal Behavior, 70, 271-286.

McKoon, G., \& Ratcliff, R. (1986). Inferences about predictable events. Journal of Experimental Psychology: Learning, Memory, and Cognition, 12, 82-91.

McKoon, G., \& Ratcliff, R. (1989). Assessing the occurrence of elaborative inference with recognition: Compatibility checking vs. compound cue theory. Journal of Memory and Language, 28, 547-563.

McKoon, G., \& Ratcliff, R. (1992). Inference during reading. Psychological Review, 99, 440-466.

Modern Chinese frequency dictionary. (1986). Beijing, China: Beijing Language Institute Press.

O’Brien, E. J., Duffy, S. A., \& Myers, J. L. (1986). Anaphoric inference during reading. Journal of Experimental Psychology: Learning, Memory, and Cognition, 12, 346-352.

Pompi, F. P., \& Lachman, R. (1967). Surrogate processes in the short-term retention of connected discourse. Journal of Experimental Psychology, 75, 143-151. 
Potts, G. R., Keenan, J. M., \& Golding, J. M. (1988). Assessing the occurrence of elaborative inferences: Lexical decision versus naming. Journal of Memory and Language, 27, 399-415.

Rayner, K., Well, A. D., \& Pollatsek, A. (1980). Asymmetry of the effective visual field in reading. Perception \& Psychophysics, 27, 537-544.

Reiser, B. J., Black, J. B., \& Lehnert, W. G. (1985). Thematic knowledge structures in the understanding and generation of narratives. Discourse Processes, 8, 357-389.

Sanford, A. J., \& Garrod, S. C. (1981). Understanding written language: Explorations in comprehension beyond the sentence. New York: Wiley.

Schank, R. C. (1982). Dynamic memory: A theory of reminding and learning in computers and people. New York: Cambridge University Press.

Schank, R. C., \& Abelson, R. P. (1977). Scripts, plans, goals and understanding: An inquiry into human knowledge structures. Hillsdale, NJ: Lawrence Erlbaum Associates, Inc.

Seifert, C. M. (1990). Content based inferences in text. In A. C. Graesser \& G. H. Bower (Eds.), Inferences and text comprehension (pp. 103-122). San Diego, CA: Academic.

Seifert, C. M., Dyer, M. G., \& Black, J. B. (1986). Thematic knowledge in story understanding. Text, 6, 393-425.

Seifert, C. M., McKoon, G., Abelson, R. P., \& Ratcliff, R. (1986). Memory connections between thematically similar episodes. Journal of Experimental Psychology: Learning, Memory, and Cognition, $12,220-231$.

Seifert, C. M., Robertson, S. P., \& Black, J. B. (1985). Types of inferences generated during reading. Journal of Memory and Language, 24, 405-422.

Singer, M. (1979). Process of inference in sentence encoding. Memory \& Cognition, 7, 192-200.

Singer, M. (1980). The role of case-filling inferences in the coherence of brief passages. Discourse Processes, 3, 185-201.

Singer, M. (1988). Inferences in reading. Reading Research: Advances in Theory and Practice, 6, $177-219$.

Singer, M., \& Ferreira, F. (1983). Inferring consequences in story comprehension. Journal of Verbal Learning and Verbal Behavior, 21, 437-448.

Singer, M., Graesser, A. C., \& Trabasso, T. (1994). Minimal or global inference during reading. Journal of Memory and Language, 33, 421-441.

Thorndyke, P. W. (1977). Cognitive structures in comprehension and memory of narrative discourse. Cognitive Psychology, 9, 77-110.

Till, R. E., Mross, E. F., \& Kintsch, W. (1988). Time course of priming for associate and inference words in a discourse context. Memory \& Cognition, 16, 283-298.

van Dijk, T. A., \& Kintsch, W. (1983). Strategies of discourse comprehension. New York: Academic.

Whitney, P. (1986). Processing category terms in context: Instantiations as inferences. Memory \& Cognition, 14, 39-48.

Whitney, P. (1987). Psychological theories of elaborative inferences: Implications for scheme theoretic views of comprehension. Reading Research Quarterly, 22, 299-310.

Williams, J. P. (1993). Comprehension of students with and without learning disabilities: Identification of narrative themes and ideosynchratic text representations. Journal of Educational Psychology, 85, 631-641.

Yang, H. M., \& McConkie, G. W. (1999). Reading Chinese: Some basic eye-movement characteristics. In J. Wang, W. Inhoff, \& H. C. Chen (Eds.), Reading Chinese script: A cognitive analysis (pp. 207-222). Mahwah, NJ: Lawrence Erlbaum Associates, Inc.

Zhang, H., \& Hoosain, R. (2001). The influence of narrative text characteristics on thematic inference during reading. Journal of Research in Reading, 24, 173-186. 
APPENDIX A

Target Words in Experiment 1

$\underline{\text { Target Word in Inference Context }}$

Text Thematic Word

(1) 贪 Greedy

(2) 慢 Tardy

(3) 害 Hurt

(4) 虚 Timid

(5) 止 Stop

(6) 根 Root

(7) 警 Wary

(8) 违 Violate

(9) 骄 Arrogant

(10) 面 Face

(11) 类 Group

(12) 恶 Vice

(13) 智 Wise

(14) 爱 Love

(15) 徒 Vain

(16) 成 Succeed

(17) 严 Strict

(18) 悔 Regret

(19) 恩 Kindness

(20) 近 Close $\underline{\text { Target Word in Unrelated Context }}$

Text Unrelated Word

(19) 贪 Greedy

(20) 慢 Tardy

(10) 害 Hurt

(8) 虚Timid

(16) 止 Stop

(15) 根 Root

(14) 警 Wary

(17) 违 Violate

(13) 骄 Arrogant

(3) 面 Face

(4) 类 Group

(18) 恶 Vice

(9) 智 Wise

(7) 爱 Love

(5) 徒 Vain

(1) 成 Succeed

(11) 严 Strict

(6) 悔 Regret

(12) 恩 Kindness

(2) 近 Close 


\section{APPENDIX B}

Target Words in Experiment 2

\section{Inference Target Word}

Text Word Frequency Class

(1) 贪 Greedy 29.9 a

(2) 慢 Tardy $267.1 \quad$ a

(3) 害 Hurt $428.6 \quad \mathrm{v}$

(4) 虚 Timid 74.7 a

(5) 止 Stop $229.0 \mathrm{v}$

(6) 根 Root $721.2 \quad \mathrm{n}$

(7) 警 Wary $133.3 \quad$ a

(8) 违 Violate $76.9 \quad \mathrm{v}$

(9) 骄 Arrogant $42.0 \quad$ a

(10) 面 Face $2629.3 \mathrm{n}$

(11) 类 Group $457.4 \quad \mathrm{n}$

(12) 恶 Vice $152.1 \quad a$

(13) 智 Wise $56.4 \quad a$

(14) 爱 Love $678.6 \quad \mathrm{v}$

(15) 徒 Vain $120.0 \quad a$

(16) 成 Succeed $2576.2 \quad \mathrm{v}$

(17) 严 Strict 373.9 a

(18) 悔 Regret $39.7 \quad \mathrm{v}$

(19) 恩 Kindness $12.2 \quad \mathrm{n}$

(20) 近 Close $506.1 \quad \mathrm{a}$
Unrelated Target Word

Text Word Frequency Class

(1) 融 Melting $29.9 \quad a$

(2) 简 Simple $269.9 \quad \mathrm{a}$

(3) 坚 Uphold $411.5 \quad \mathrm{v}$

(4) 苻 Respectable $75.2 \quad a$

(5) 待Wait $222.9 \quad \mathrm{v}$

(6) 步 Step 673.6 n

(7) 默 Silent $\quad 127.2 \quad$ a

(8) 典 Pawn $76.3 \quad v$

(9) 懒 Lazy 40.9 a

(10) 民 Civilian 2653.0 n

(11) 席 Mat $462.9 \quad \mathrm{n}$

(12) 圆 Round 149.9 a

（13）脆 Fragile 56.4 a

(14) 算 Calculate $627.2 \quad \mathrm{v}$

(15) 齐 Neat 120.0 a

(16) 用 Employ $2876.5 \quad \mathrm{v}$

(17) 複 Complex $366.1 \quad a$

(18) 隆 Swell 37.6 v

(19) 雁 Goose 12.2 n

(20) 深 Deep 496.7 a 
Copyright of Discourse Processes is the property of Lawrence Erlbaum Associates. The copyright in an individual article may be maintained by the author in certain cases. Content may not be copied or emailed to multiple sites or posted to a listserv without the copyright holder's express written permission. However, users may print, download, or email articles for individual use. 